\title{
Wetland Community Center Design Based on Environmental Contexts and Local Identity
}

\author{
Teerintra Sirisawad, Piyakarn Teartisup, Songkiat Teartisup, and Prapeut Kerdsueb
}

\begin{abstract}
The objective of this research is finding the way to design architectures harmonized with the environmental contexts and represented local identity. This research emphasizes cognitive analysis and contemplation of the relationships between environmental factors and their effects to local design by using matrix analysis in order to find out the solutions in sustainable design by using documentary research and a site survey. In addition, this research focus on vernacular architectures which were designed related to and with respect to their environments in various dimensions, such as natural, social, cultural, and economic. Moreover, they contain environmental friendly concepts that appear on their physical design, detail design, and layout planning. The case study site is Huai Jorakaemak (HJK) non-hunting area, Northeastern of Thailand that the one of the RAMSAR list of Wetlands International Importance and Eastern Sarus Crane reintroduction site. The output can apply these concepts into the real architectural design process, so that architects, planners, and environmentalists can create sustainable architecture and a sustainable environment for local community development.
\end{abstract}

Index Terms-Architectural design, vernacular architecture, environmental contexts, local identity, landscape ecology.

\section{INTRODUCTION}

Vernacular architecture is a representative element which reflects local identity. Because of its concept respects to its contexts and it conforms to traditional way of life. If considered overall environmental contexts in local area for example vegetation, topography, climate and local materials, are all significant factors that affect the style of local architecture. It formed by basic requirements which responding to daily local life and showing the ability to manage their limited resources effectively. In addition vernacular architectures express creativity and wisdom of local people in architecture design as well as living in harmony with their environment perfectly [1]. Understanding of vernacular architecture is an important intellectual to develop the sustainable design concept and process to create architectures in harmony with the environment. This knowledge also guides the implementation of architectural design for the future which will affect people's lives, natural resources, environment and Energy. Moreover it leads to make conscious, value highly with the local resources they

Manuscript received May 15, 2014; revised July 25, 2014.

Teerintra Sirisawad is with School of Architecture and Fine Arts, University of Phayao, Thailand.

Piyakarn Teartisup and Prapeut Kerdsueb are with the Faculty of Environment and Natural Resource Studies, Mahidol University, Thailand (e-mail: tpiyakarn@gmail.com).

Songkiat Teartisup is with the Faculty of Architecture, King Mongkut's Institute of Technology Ladkrabang, Thailand. will be proud of cultural heritage in their community and finally these will be an essential social costs to help strengthen the community further [2]. Because of the community identity both environmental and traditional dimension have abundant effects on people's paradigm shifts and the direction of community development [3]. These bodies of knowledge caused by learning, collecting and passing on knowledge from generation to generation. They are the affinity with environment by utilizing natural energy, reducing wastes and harmonize with ecology. Huai Jorakaemak (HJK) non-hunting area, Northeast of Thailand is a case study site that an important international wetland. It provides foods and habitats for various kinds of birds, waterfowls and also aquatic animals and Eastern Sarus Crane reintroduction site [4]. This spatial ecology is considered as a conservation area [5]. For motivating the country into the sustainable way, it is necessary to balance between conservation and consumption. The conservation and wise use of all wetlands through local and national actions and international cooperation, as a contribution towards achieving sustainable development throughout the world.

\section{Methodology}

The objective of this research is finding the way to design architectures harmonized with the environmental contexts and represented local identity. It is necessary to use mixed-methods in this study for collecting involved data both international knowledge and local knowledge. Therefore documentary research, site survey and structure observation are used for aggregating data. Then analyzing the relationship between environmental contexts and local identity with the impacts to local architectures by matrix analysis and mind map summary. After that discuss and evaluate by using SWOT analysis and explanatory. Finally, synthesis and applied body of knowledge to practical part that is a case study, community center design at HJK non-hunting area by proceeding architectural design process. For the purpose that to suggest schematic designs of appropriate architectures which are designed based-on environmental contexts and local identity.

\section{RESUlts}

\section{A. Sustainable Architectural Design Factors}

Sustainability is a humanistic issue which has come to mean all things to all people. It is really a system that will continue to evolve for a sustainable architecture with its surroundings. So that, sustainable design based on holistic approach can bring a greater connectivity between people's 
well-being, environmental considerations, technological possibilities and nature itself which is fundamental to a sustainable future. It is common to attempt to minimize the environmental impacts of buildings by selecting environmental criteria which are used to inform the design process. BREEAM, a UK Sustainable Building Code issued in 2006, describes the environmental factors involved in compliance. We believe this is a better description for environmental considerations in sustainable design. Also, it is better to employ the economic and social factors in the sustainable design process.

Appropriate architectural design should concern multi-factors and contexts, especially environment. The research found that climatic factor such as rain; wind; humidity; and sunlight are the key factors effect on architectural design [6]. The three strategies for the economy of resources principle are energy conservation, water conservation and material conservation. Each focuses on a particular resource necessary for building construction and operation. Energy conservation; after construction, a building requires a constant flow of energy input during its operation [7]. Other issues of interest can be included in relation to the profile of the building. For instance, a green project might also choose to include the following design parameters biodiversity (vegetation and wildlife), life cycle assessments for the materials applied in the building and reduced private transportation [8]. Architectural Factors consist of 1) natural factors 2) physical factors 3) social and cultural factors 4) technological factors and 5) aesthetic factors [9]. According with the other research found that social-cultural structure, economy, materials and technology are significant roles shaping the architecture [6]. Moreover, factors that determine characteristic of built environment are 1) size of human 2) what human need for life and comfort 3 ) activities 4) the land 5) materials and 6) methods [10]. The contemporary architectural design, which focuses on harmonizing with environment, economy, social and culture, aims to express local identity of each local area. The main criteria are 1) harmonize with location and micro climate 2) use local materials 3) adapt some traditional physical element 4) use currently materials and technology 5) apply the traditional concept and 6) integrate with local life-style and human behaviors on using space [11]. Unless the architecture, landscape design and site planning should be based-on the site and surrounding contexts which compost with natural factors, cultural factors and aesthetic factors [12]. Factors affecting the urban form of self-built environments have been investigated by several theorists who grouped them according to different categories. These factors are: (Location, Topography, Climate, Land sub-division, Economical factor, Socio-cultural factor, Building materials/ methods). They have several physical variables, that affected directly by the factors of self-built environments are Open Space, Road Hierarchy, Settlement Pattern, Town, Cramming, Districts, Building Lines, Density, Layout, Street Pattern, Block Size, Edge, Incremental Design, Nodes, Space Network, Street, Width, Block Shape, Unity, Massing, Materials, Color, Focal Points, Form, Landmarks, Rhythm, Roof scape, Skyline, Texture, Openings, Elevation Width, Enclosure, Variety, Gateway,

\section{Human Scale [13].}

In vernacular architecture, it is equally reasonable for people in daily connection with nature to seek its conquest through processes that smooth the rough and brighten the dull, altering the natural into artificial. Local materials are their resources, their technologies are powered by their own muscles, but their aim is to create emblems of cultural presence. These concepts of design are sustainability way [14]. Vernacular architecture is surely a contradiction in terms. The vernacular is the unconscious work of craftsmen based on knowledge accumulated over generations the very opposite of architecture, which involves a premeditated design process with a conscious appeal to the intellect. Yet, the term is convenient shorthand to describe an approach that adopts the spirit of the vernacular; if not its actual forms it is not intended to indicate a new style [15]. When the vernacular technologies involve local materials and touch of the hand, their contrast is with industrial systems of production. Where, vernacular technology depends on their direct connections [16]. The principles of sustainable are on the same direction of that of the vernacular as the relation between the built environment and the surrounding nature. The change of ecology, mixing culture, technology and economic development has changed the vernacular architecture. The effects are related to each other, the ecology is affected by the technology then the technology is affected by the condition of economic. Economic also brought effect to the culture and so on. The architectonic concepts have been pronouncedly affected by multifarious cultural influences brought along by several invaders, colonizers, missionaries, merchants and traders. Traditionally, the most significant foreign architectural influences have affected the building styles and techniques [17].

Due to the forced pace of modernization, the conflict between traditional values and imported ideas has been quite sharp in some countries, and recently the resulting resentment gave rise to fundamentalist movements. A massive import of architectural language as a stereotype vocabulary of built form that is essentially Western in character. Yet it is being associated worldwide with images of progress, prestige, and future orientation. In turn, it has largely influenced the indigenous values of architecture. Dramatic change and innovation have been part of modernity for centuries, as has technological development and expansion. Yet these phenomena, bound up with globalization in its current phase, have created enough novelties to require a rethinking of social theory and politics in the current situation as a response to new developments in society and culture. Architects working in the ivory tower of their rational dreams produce architecture that is universally applicable but lacking truth and relevance, as it is no longer supported by a corresponding cultural identity. For some theorists and architects, globalization is seen as a process of standardization in which a globalized media and consumer culture circulate the globe, creating "sameness" everywhere, thus bringing to light the bland and boring universality in modern projects [18].

\section{1) Environment contexts}

The science of Environment studies is a multi-disciplinary science because it comprises various branches of studies like 
chemistry, physics, medical science, life science, agriculture, public health, sanitary engineering etc. It is the science of physical phenomena in the environment. It studies of the sources, reactions, transport, effect and fate of physical a biological species in the air, water and soil and the effect of from human activity upon these [19]. Literary environment means the surrounding external conditions influencing development or growth of people, animal or plants; living or working conditions. Element of Environment; environment is constituted by the interacting systems of physical, biological and cultural elements inter-related in various ways, individually as well as collectively. These elements may be explained as 1) Physical elements; physical elements are as space, landforms, water bodies, climate soils, rocks and minerals. They determine the variable character of the human habitat, its opportunities as well as limitations, 2) Biological; elements biological elements such as plants, animals, microorganisms and men constitute the biosphere, 3) Cultural elements Cultural elements such as economic, social and political elements are essentially manmade features, which make cultural environment. Environment is of three types which influence the personality of an individual as physical environment, social and cultural environment and psychological environment. These may be explained that 1) physical environment refers to geographical climate and weather or physical conditions wherein and individual lives. The human races are greatly influenced by the climate. The physique of an individual depends on climate conditions as the individual tries to adjust in his physical environment and the human working efficiency also depends on the climatic conditions, 2) Social Environment includes an individual's social, economic and political condition wherein he lives. The moral, cultural and emotional forces influence the life and nature of individual behavior. Society may be classified into two categories are opened society that is very conductive for the individual development and closed society which is not very conductive for the development, 3) Psychological Environment; although physical and social environment are common to the individual in a specific situation or can used the term 'life space' for explaining psychological environment. The Psychological environment enables us to understand the personality of an individual. Both the person and his goal form psychological environment. If a person is unable to overcome the barriers, he can either get frustrated or completed to change his goal for a new psychological environment. But adopting this mechanism, the individual is helped in his adjustment to the environment. Environment is both physical and biological. It includes both living and non-living components. The Physical Environment is classified into three broad categories (i) Solid, (ii) Liquid (iii) Gas. These represent the following spheres: (i) The lithosphere (solid earth) (ii) The hydrosphere (water component) and (iii) The atmosphere As such, the three basic of physical environment may be termed (i) Lithospheric Environment (ii) Hydrospheric Environment (iii) Atmospheric Environment. The scientists have classified them into smaller units based on different spatial scales, e.g. (i) Mountain Environment (ii) Glacier Environment (iii) Plateau Environment (iv) Coastal Environment. The biological of the environment consists of: (i) Plants (flora) (ii) Animals (fauna). Thus, the biotic environment further be divided into floral environment and faunal environment. All the organisms work to form their social groups and organizations at several levels. Thus, the social environment is formed. In this social environment the organisms work to derive matter from the physical environment for their sustenance and development. This process gives birth to economic environment.

\section{2) Landscape ecology}

Landscape ecology is the study of landscapes; specifically, the composition, structure and function of landscapes. Although there are myriad ways to define 'landscape' depending on the phenomenon under consideration, suffice it to say that a landscape is not necessarily defined by its size; rather, it is defined by an interacting mosaic of ecosystems elements relevant to some phenomenon under consideration at any scale. Thus, a landscape is simply an area of land at any scale containing an interesting pattern that affects and is affected by an ecological process of interest. Landscape ecology, then, involves the study of these landscape patterns, the interactions among the elements of this pattern, and how these patterns and interactions change over time. In addition, landscape ecology involves the application of these principles in the formulation and solving of real-world problems. Landscape ecology is perhaps best distinguished by its focus on 1) spatial heterogeneity, 2) broader spatial extents than those traditionally studied in ecology and 3 ) the role of humans in creating and affecting landscape patterns and process. Landscape ecology might be defined best by its focus on spatial heterogeneity and pattern. As such, landscape ecology has five central themes; 1) Detecting pattern and the scale at which it is expressed, and summarizing it quantitatively. 2) Identifying and describing the agents of pattern formation, which include the physical abiotic template, demographic responses to this template, and disturbance regimes overlaid on these. 3) Characterizing the changes in pattern and process over space and time; that is the dynamics of the landscape, and summarizing it quantitatively. 4) An interest in landscape dynamics necessarily invokes models of some sort because landscapes are large and they change over time scales that are difficult to embrace empirically. 5) Understanding the ecological implications of pattern; that is why it matters to populations, communities, and ecosystems. This is the stuff of conservation biology and ecosystem management to achieve human objectives. Landscape ecology is distinguished by its focus on broader spatial extents than those traditionally studied in ecology. This stems from the anthropocentric origins of the discipline. Initial impetus for the discipline came from the geographic aerial view of the environment, for example, the patterns in the environment visible from an aerial photograph. The focus on large geographic areas is consistent with how humans typically see the world-through a coarse lens. However, modern landscape ecology does not define, a priori, specific scales that may be universally applied; rather, the emphasis is to identify scales that best characterize relationships between spatial heterogeneity and the process of interest. Landscape ecology is often defined by it focus on the role of humans in creating and affecting 
landscape patterns and process. Indeed, landscape ecology is sometimes considered to be an interdisciplinary science dealing with the interrelation between human society and its living environment. Hence, a great deal of landscape ecology deals with 'built' environments, where humans are the dominant force of landscape change. However, modern landscape ecology, with 2 its emphasis on the interplay between spatial heterogeneity and ecological process, considers humans as one of many important agents affecting landscapes, and emphasizes both natural, semi-natural, and built landscapes [20].

\section{3) Local Identity}

When defining the concept of identity, it is necessary to recognize the complexity of identity formation; his method of establishing the desired functional and symbolic connections between an environment and people privileges ethnicity above all other identity-constructing factors [21]. The concept assumes that identity comes from using available cultural resources from a spectrum of cultural presentations [22]. Place identity is also defined precisely as a set of cognitions about physical settings. The concept of place identity underpins the collective sense of cultural identification with a particular building and its design features. Within the last few years, globalization has become a catch phrase in architecture associated with a loss of place identity. There seems to be a general consensus that identity plays a significant role for the continuity of man's culture; otherwise, he will be cut off from his past. Place identity is attracting increasing interest from both architects and planners, as well as in social-science research. The phrase "place identity" conveys many different dimensions such as physical size, tangible versus symbolic, and known and experienced versus unknown or not experienced. Place also includes that which influences the meaning occupants give to it through personal, social, and cultural processes [23]. Therefore, place can be described in terms of many multidimensional physical and psychological environmental attributes. Individuals' psychological sense of place identity can be understood in many ways: as an experience, a convergence of cognitions, how residents feel towards their town, or an assessment of the extent to which they agree with the sentiment "this is not the place for me." Place identity is sometimes described as an implicit psychological structure; it is also considered a cognitive structure that contributes to global categorization and social-identity processes. It emerges from involvement between people and place. It is described as the individual's incorporation into the larger concept of self to denote the dimensions of self that define an individual's personal identity in relation to physical environment. The concept of place identity sometimes is belongingness, refers to conscious ties between the community and its residents as these develop over time and an interpretation of the self that uses place, a significant, symbolic locale, as a sign or locus of identity. It considers places environmental contexts with real consequences for people and lays a great deal of stress on ties between the place and the people. It can be extended identity theory to the area of environmental psychology and proposed that place identity is a physical world socialization of the self [24]. This concept considers the debate around decisions with regard to buildings and the sources of architectural elements used in the design project or building. It implies that there are essential natural characteristics that identify a place and that, in effect, these are latent and without structure but can be released by a sensitive design solution. Under this criteria, a locally appropriate building or proposed project is determined by a general consensus on the building and/or proposed project with incorporation of an acceptable architectural language drawn from vernacular design aspects, including site, vernacular architectural forms, materials, and symbolism. It also considers the setting of buildings and the sources of architectural elements used in the design project or building. Under this, a locally appropriate building or proposed project could be determined by a general political consensus on the proposed project with incorporation of an acceptable architectural language drawn from the national vernacular language. Obviously, we mean a totality made up of concrete things having material substance, shape, texture, and color together determining the essence of place, where place is seen as a product of physical attributes. How did these theoretical developments with regard to the concept of identity impact architectural thinking? More specifically, the study focuses on the expression of identity in architecture to assist us in improving our understanding of the nature of the relationship between built form and culture through identification of pertinent elements in the built environment [25].

As a result, we suggest a list of factors that it should be considered in sustainable design, which is shown in Table I.

\begin{tabular}{|c|c|}
\hline Categories & Factors \\
\hline Land use and Ecology & $\begin{array}{l}\text { Ecological value of site } \\
\text { Ecological enhancement } \\
\text { Protect of ecological features } \\
\text { Change in ecological value of } \\
\text { site } \\
\text { Building footprint }\end{array}$ \\
\hline Microclimate & $\begin{array}{l}\text { Vegetation } \\
\text { Wind mitigation/channeling } \\
\text { Topography }\end{array}$ \\
\hline Materials & $\begin{array}{l}\text { Environmental impact of } \\
\text { materials } \\
\text { Responsible sourcing of } \\
\text { materials -basic building } \\
\text { Elements and finishing elements }\end{array}$ \\
\hline Waste & $\begin{array}{l}\text { Storage of non-recyclable waste } \\
\text { and recycle household waste } \\
\text { Construction waste management } \\
\text { Composting }\end{array}$ \\
\hline Energy and $\mathrm{CO} 2$ emission & $\begin{array}{l}\text { Dwelling emission rate } \\
\text { Building fabric ,Drying space } \\
\text { Internal Light and External light } \\
\text { Energy labeled white goods } \\
\text { Low or zero carbon technologies } \\
\text { Cycle storage } \\
\text { Home office }\end{array}$ \\
\hline Pollution & $\begin{array}{l}\text { Global warming } \\
\text { NOx emissions }\end{array}$ \\
\hline
\end{tabular}

\section{B. Vernacular Zone}

Northeastern of Thailand is in Korat Plateau which is an elevated basin. There is Mekong river and it flows through the northern to southeastern parts of this Plateau. Inside the Plateau is effected by Mun river (sub-watershed of Mekong basin). The climate is monsoon rainfall pattern, rainfall 
during the early months of the wet season will be increased especially July. The dry spell between the early season rain peak and late season rain peak will be reduced from 3 months (July-September) to 2 months (July-August). The rainy season begins with occasional short but heavy rain, eventually raining very heavily for longer periods almost every day, usually in the late afternoon or at night, until it ends abruptly at the onset of the dry season in October to February. Biological changes are depending on physical and climatological changes, in which the faunal abundance and diversity are confined to rocks deposited by the meandering river system.

\section{Vernacular Architecture in Northeastern (NE)}

\section{1) Housing architecture: Permanent house}

Ruan Keoi is a traditional NE house which has a porch extended from the main house. This porch can be used as a kitchen, recreation area, guest area and other uses rituals and traditional activities for NE people. The lower floor is used as a storehouse for storing utensils and also sometimes for handicraft activities and livestock.

Ruan Khong is a small building or small house that has its own distinguished structure, but it is built attached to the porch of the main house. When it needs to be removed, it can be taken directly without damaging the structure of the main building.

Ruan Fan (Twin house) was built in parallel, the structure of the houses were connected.

Ruan Phu Tai is similar to Ruan Khong but slightly difference that is the structure (beam and bar) of the small house is attached to the structure of the main house. Phu Tai is ethnic group only found in NE.

Khmer houses are rectangular 2 storey buildings as varying in many sizes. The basic structure consists of a wooden frame, and the roof is erected before the walls on the upper floor are inserted. The roof frame defines the type of the house: a gabled roof, a hipped or mansard roof. A common feature in every type of house is a $5-10 \mathrm{~cm}$ gap, on all four sides, between the top of the wall of the upper floor and the roof.

Ruan Korat is a house located in Nakhon Ratchasima, province in NE. That house made from wood and some decorative element.

\section{2) Housing architecture: Semi-permanent house}

Toob Tor Lao is a temporary building which stretches from Lao Khao as residence of a new family which cannot afford building a new house. A new family lives separately from the parents but still in the same area. If there is no resident, the barn can be used as a storehouse also.

Toob Yao is a small temporary as residence of a new family which cannot afford building a new permanent house. Toob Yao usually made of simple materials such as bamboo, wood and grass.

\section{3) Agricultural architecture}

Lao Khao (Barn) is used for keep paddy rice, agricultural products, everyday-life utensils and pen for livestock.

\section{Analyze Vernacular Architecture}

\section{1) Space and form}

$\mathrm{NE}$ vernacular architectures reflect their relation between local wisdom harmonize with their natural and cultural surrounding. The change of ecology, mixing culture, technology and economic development has changed the vernacular architecture. The effects are related to each other, the ecology is affected by the technology then the technology is affected by the condition of economic. Economic also brought effect to the culture and so on. Local bodies of knowledge influence have affected the building styles and techniques.

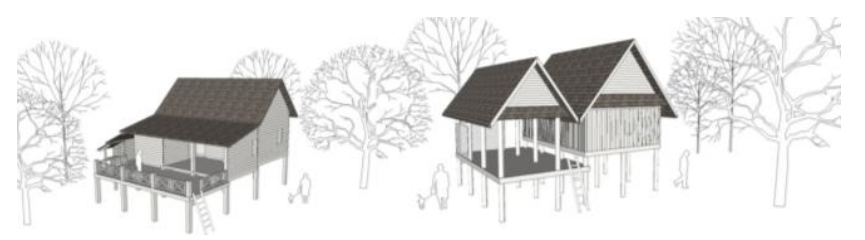

Fig. 1. Space and form of NE vernacular architecture.

\section{2) Materials and constructions}

Main materials that use in NE vernacular architecture are wood and bamboo which local people can be found easily around their community. Wood and bamboo were used for structure of the building, finishing and decorated ornament also. In vernacular architecture, it is equally reasonable for people in daily connection with nature to seek its conquest through processes that smooth the rough and brighten the dull, altering the natural into artificial. Local materials are their resources, their technologies are powered by their own muscles, but their aim is to create emblems of cultural presence.

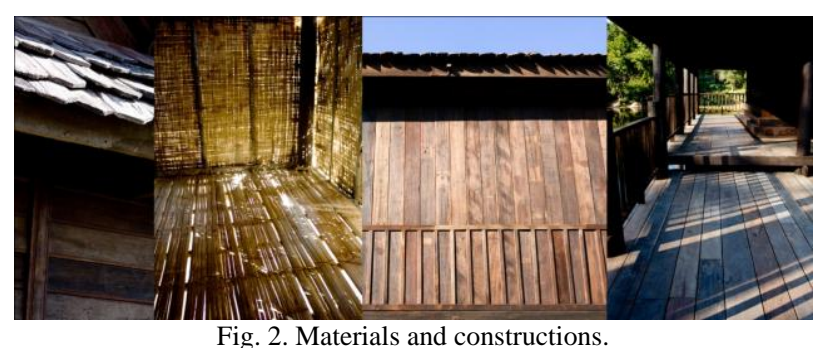

\section{3) Connection to environmental contexts}

Despite the seemingly close correlation between the design principles and issues or concerns of the different approaches, there are large differences in the scale of focus which determines the strategy associated with the respective design principles in relation to e.g.: A global (climate and technology) vs. a local (nature and culture) scale of focus And the scale of the design: urban development, site planning, building design and building components. There are also differences in the approaches to the main issues or concerns, where some approaches are concerned with the human impact on both nature and climate; other approaches are mainly concerned with the climatic or the natural consequences associated with lifestyles.

$\mathrm{NE}$ vernacular architectures use natural ventilation systems that rely on natural driving forces, such as wind and temperature difference between a building and its environment, to drive the flow of fresh air through a building. Both work on the principle of air moving from a high pressure to a low pressure zone. Cross ventilation depends on two continuously changing factors: wind availability and 
wind direction. Consequently, it is a somewhat unreliable source for providing air flow and thermal comfort. In cross ventilation the wind creates a high pressure zone where it impacts the building and a low pressure zone on the leeward side, drawing air through the building.

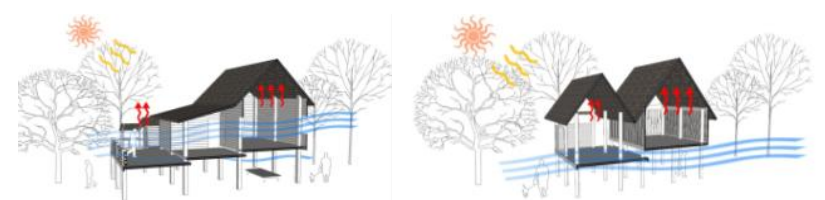

Fig. 3. Natural ventilation- Ruan Keoi and Ruan Phu Tai.

\section{4) Relate to local identity}

Land use planning, urban open space for community is a public area for community activities. The landscape of urban open spaces can range from playing fields to highly maintained environments to relatively natural landscapes. They are commonly open to public access, however, in the $\mathrm{NE}$ local community has a unique sequence of space.

\section{E. Wetland Community Center}

HJK non-hunting area consists of several function and different activities. Because of the fact that, it should have to concern about the effects that might be caused by development. Nowadays, populations are increasing; the settlement of communities, the development of public facilities and the construction of buildings were widespread into the area. Meanwhile, there were growing needs of the people. At that period, abundant natural resources had been seen as an asset to be exploited in social development. The short term economic advancement was based on a policy which overlooked the impacts of development on the environment in the long run. This led to the decline of natural resources.

The office Of HJK non-hunting area propose to create a new community center for local people and external visitors who want to learn about the wetland ecology, waterfowls and local culture also. This program was adapted from the requirement and concept design from Habitat for Humanity, who has decided as a way to create community that its organization, will begin sponsoring the building of community centers in many of the communities where it has been involved in building homes. Recognizing that communities, cultures, environments, and resources are wide ranging, they are endeavoring to begin this new project focus by commissioning different designs such as gathering space for 30-50 people; garden/outdoor gathering for 75-100 with stage; variety of garden spaces; food preparation area/kitchen to be used for community events; storage; restrooms (2-can be detached); and 2 parking spaces.

This is a case study concept uses some traditional and vernacular elements applying to create new community center. Materials and constructions will be mixed both local and new appropriate materials.

\section{F. SWOT Analyze}

It indicated that this design concept has strengths in harmonizing with the contexts, energy efficiency, expressing local identity and integrated various dimension. While the weaknesses are lacking of participatory process with local

people, less concern about maintenance after construction process and should be more research about new materials and technologies together. The opportunities of this approach are the trend of sustainability and global warming/climate change alert. The last one, the threats of this study are lacking of in-depth research and application for take a real action in architectural design process. Moreover do not have knowledge management of local wisdom or local techniques in architectural design. However the modernism trends of architecture still have effects on today architectural design undeniable.

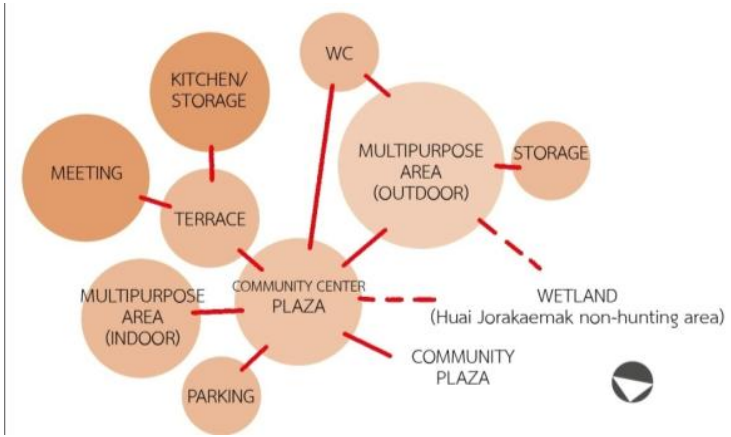

Fig. 4. Design diagram related to site.

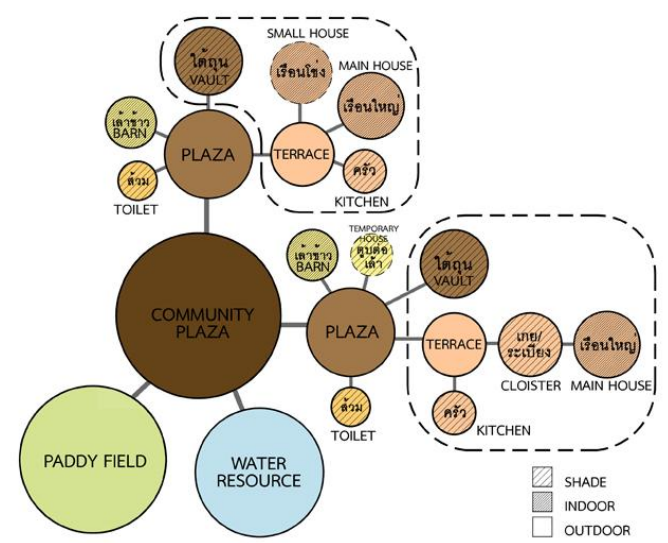

Fig. 5. Local space diagram.

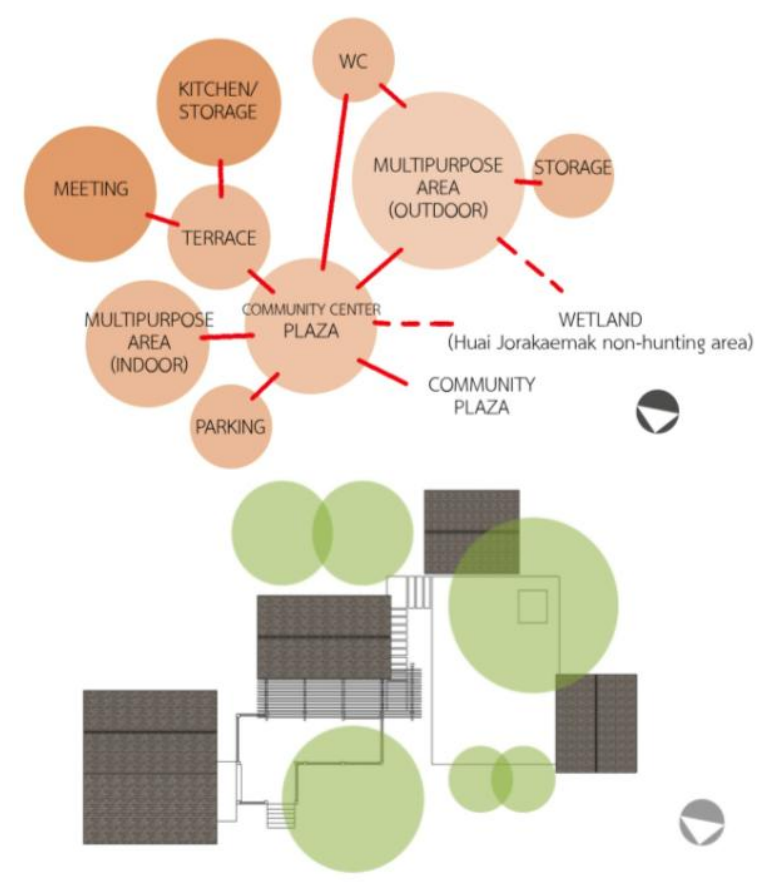

Fig. 6. Schematic design suggestion: Site planning. 


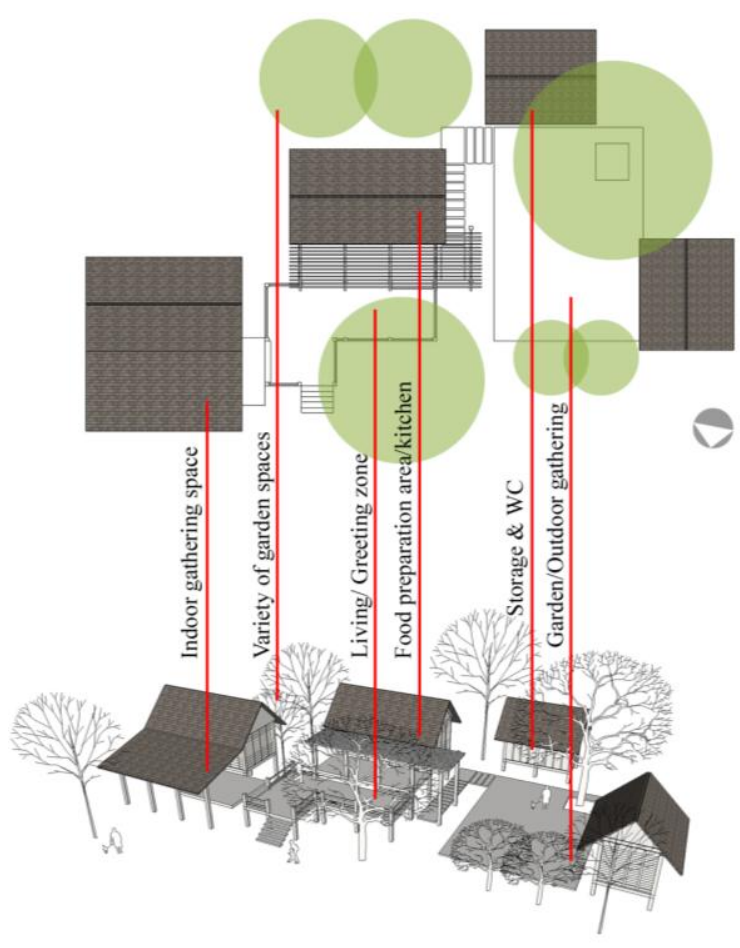

Fig 7. Schematic design suggestion: Mass-form-space.

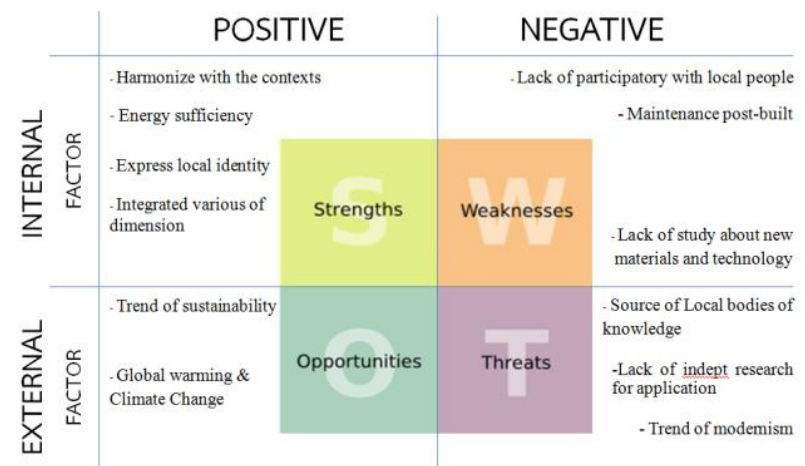

Fig. 8. SWOT analysis analyzes results of the study.

\section{CONCLUSIONS}

The principle of architecture design based on environmental contexts and local identity were

1) based on conception of respecting the nature and the acceptable levels of global resource depletion and environmental pollution,

2) Satisfied the needs of joint, sustainable and harmonious development between humans and nature.

3) Made full use of natural resources according to rule of less consumption and more utilization.

4) Used suitable measures to local conditions to creating friendly environment. The fundamentals of passive design are to link buildings with their environments and microclimate.

5) Created flexibility for buildings by adjusting links in designing process.

From the result of documentary research showed that some of the significant factors were ignored in the architectural design process. For example disaster, drainage, water resource, plant, pollution, these factors are necessary to concern for create sustainable architecture and well-being.

The sustainable concept in architectural design is very board and so ideal. The most important thought is how to put those concepts into real process of architecture design. While it is necessary to consider multi-factor that might be affected from architectural process, it should be focus on detail design in each process in the same time.

\section{REFERENCES}

[1] W. Temeeyapan, The Heritage of the Local Thai Environment, Bangkok: King Mongkut's Institute of Technology Ladkrabang, 2004.

[2] C. Wetakarn, Visual Arts Knowledge Management by Cultural Communities, Bangkok: CU Press, 2008.

[3] W. P. Stewart, D. Liebert, and K. W. Larkin, "Community identities as visions for landscape change," Landscape and Urban Planning, vol. 69, pp. 315-334, 2003.

[4] ONEP, EIA of Thailand, Bangkok: ONEP, 1999.

[5] ONEP, Strategic Environmental Assessment: SEA, Bangkok: ONEP, 2002.

[6] N. Engin, N. Vural, S. Vural, and M. R. Sumerkan, "Climatic effect in the formation of vernacular houses in the Eastern Black Sea region," Building and Environment, vol. 42, 2007.

[7] J. J. Kim, Sustainable Architecture Module: Introduction to Sustainable Design, National Pollution Prevention Center for Higher Education, University Ave., Ann Arbor, 1998.

[8] A. K. Mary, T. R. H. Hanne, and B. Camilla, "Approaches to the design sustainable housing with low $\mathrm{CO}_{2}$ emission in Denmark," Renewable Energy, vol. 34, 2009.

[9] M. Kyndrup, Den Astetiske Relation, Sanseoplevelsen mellem kunst, Copenhage: Gyldendal, 2008.

[10] L. Satapitanon, Principle of Architecture, Bangkok: CU Press, 2008.

[11] K. Sinthusak, Principle of Design, Bangkok: CU Press, 2002.

[12] N. Tangsakul, Concept of Architectural Design by Local Identity, Khon Khen: KKU Press, 2003.

[13] D. Boonkhum, Site Planning, Bangkok: CU Press, 2011.

[14] H. Ibrahim, "An analytical comparative approach to the relationship between spontaneous and vernacular settlements," Faculty of Engineer, Cairo University, Giza, Egypt, 2000

[15] A. Oikonomou and F. Bougiatioti, "Architectural structure and environmental performance of the traditional buildings in Florina, NW Greece," Building and Environment, vol. 46, pp. 669-689, 2011.

[16] A. A. Tamer and M. S. Indjy, "New Strategy of upgrading slum areas in developing countries using vernacular trends to achieve a sustainable housing development," Energy Procedia, Elsevier Ltd., vol. 6, pp. 228-235, 2011.

[17] H. Glassie, Vernacular Architecture, Indian University press, p. 31, 1999.

[18] A. Husna, Healthy Building for the Earth Vernacular Architecture as Sustainable Term of Housing; Case Study in Indonesia, Institute of technology Surabaya, Indonesia, 2009.

[19] I. M. Eldemery, "Globalization challenges in architecture," Journal of Architecture and Planning Research, vol. 26, no. 4, pp. 343, Winter, 2009.

[20] J. Gajaseni, Human and Environment, Bangkok: CU Press, 2009.

[21] M. G. Turner, R. H. Gardner, and R. V. O’Neill, Landscape Ecology in Theory and Practice: Pattern and Process, Springer, New York, 2001.

[22] A. Rapoport and G. Hardie, "Cultural change analysis: Core concepts of housing for the Tswan, Housing the poor in the developing world," London and New York: Routledge, pp. 35-61, 1991.

[23] M. Mthethwa, "Towards a regional identity," Journal of Open House International, vol. 27, no. 3, pp. 54-56, 2002.

[24] G. Burd, "The research for natural regional space to claim and name built urban place," Journal of Architectural and planning research, vol. 25, no. 2, pp. 130-144, 2008.

[25] H. Proshansky et al., "Place-identity: Physical world socialization of the self," Journal of Environmental Psychology, vol. 3, no. 1, pp. 57-83, 1983.

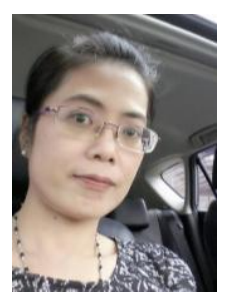

Piyakarn Teartisup is working as a lecturer at the Faculty of Environment and Natural Resource Studies, Mahidol Univ. She got the Ph.D. degree from Kasetsat University in forestry-watershed management. Her papers include: P. Teartisup, P. Kerdsueb and P. Wattaya, "Field scale mapping of soil salinity on spatial interpolation techniques, case study: Khorat Basin, Nakhon Ratchasima Province, Thailand," International Society in Environmental Information 
Sciences Environmental Informatics Archives, ISSN 1811-0231/ ISEIS, 2007. Piyakarn Teartisup and Prapeut Kerdsueb, "Application of Mike 11 for Water Quality Assessment at U-Tapao Canal, Southern of Thailand," KKU Science Journal, Faculty of Science, Khon Kaen University, Thailand, vol. 4, Year 39, 2012. P. Teartisup and P. Kerdsueb, "Land subsidence prediction in central plain of Thailand," International Journal of Environmental Sciences and Development, vol. 4, 2013, and Prapeut Kerdsueb and Piyakarn Teartisup, "The use of geoinformatics for estimating soil organic matter in central Plain of Thailand," International Journal of Environmental Science and Development, vol. 5, 2014

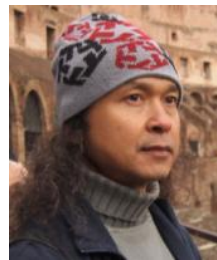

Prapeut Kerdsueb is a lecturer at the Faculty of Environment and Natural Resource Studies, Mahidol Univ. His papers include: P. Teartisup, P. Kerdsueb, and P. Wattaya, "Field scale mapping of soil salinity on spatial interpolation techniques, case study: Khorat Basin, Nakhon Ratchasima Province, Thailand," International Society in Environmental Information Sciences Environmental Informatics Archives, ISSN
1811-0231/ ISEIS, 2007. Piyakarn Teartisup and Prapeut Kerdsueb, "Application of Mike 11 for water quality assessment at U-Tapao Canal, southern of Thailand," KKU Science Journal, Faculty of Science, Khon Kaen University, Thailand, vol. 4, 2012. P. Teartisup and P. Kerdsueb, "Land subsidence prediction in central plain of thailand," International Journal of Environmental Sciences and Development, vol. 4, 2013, and Prapeut Kerdsueb and Piyakarn Teartisup, "The use of geoinformatics for estimating soil organic matter in central plain of Thailand," International Journal of Environmental Science and Development, vol. 5, 2014. 